\title{
Cutoff of $25 \%$ for Ki67 expression is a good classification tool for prognosis in colorectal cancer in the AJCC-8 stratification
}

\author{
GUOJUN TONG ${ }^{1,2}$, GUIYANG ZHANG ${ }^{1}$, JIAN LIU ${ }^{1}$, ZHAOZHENG ZHENG $^{1}$, \\ YAN CHEN $^{1}$, PINGPING NIU ${ }^{2}$ and XUTING XU ${ }^{2}$ \\ ${ }^{1}$ Department of Colorectal Surgery; ${ }^{2}$ Central Laboratory, Huzhou Central Hospital, Huzhou, Zhejiang 313000, P.R. China
}

Received October 19, 2019; Accepted February 4, 2020

DOI: 10.3892/or.2020.7511

\begin{abstract}
Ki-67 expression has been widely used in clinical practice as an index to evaluate the proliferative activity of tumor cells. The cutoff for Ki67 expression in order to increase the prognostic value of Ki67 expression in colorectal cancer varies. The present study assessed the relationship between the $25 \%$ cutoff for Ki67 expression and prognosis in colorectal cancer in the AJCC-8 (American Joint Committee on Cancer 8 edition) stratification. The current trial included 1,090 colorectal cancer patients enrolled from 2006 to 2012 at Huzhou Central Hospital. Ki67 expression was classified according to $25 \%$ intervals, dividing the patients into four groups. Measurement data were analyzed by ANOVA, and count data by Crosstabs. Bivariate correlation analysis was performed to assess clinicopathological indicators based on Ki67 expression. Disease-free survival (DFS) and overall survival (OS) based on Ki67 levels were analyzed by the Kaplan-Meier method. A total of 1,090 patients of the 2,080 enrolled CRC cases were evaluated (52.4\%). Invasive depth, tumor differentiation, tumor size, AJCC-8, positive number of lymph nodes and chemotherapy status showed significant differences in the various Ki67 expression groups (all $\mathrm{P}<0.05$ ), with significant correlations (Spearman rho: $0.170,0.456,0.22,0.195,0.514$ and -0.201 , respectively, all $\mathrm{P}<0.001)$. DFS and OS for the different Ki67 level groups based on AJCC-8 stratification were analyzed, and no significance was found in stage IV $(\mathrm{P}=0.334)$. DFS and OS survival rates were assessed at different Ki67 expression levels, and no significant differences were found (all $\mathrm{P}>0.05$ ). Cox regression analysis showed that invasive depth, lymph node metastasis, tumor differentiation, AJCC-8 and Ki67 were independent factors affecting colorectal cancer
\end{abstract}

Correspondence to: Dr Guiyang Zhang, Department of Colorectal Surgery, Huzhou Central Hospital, 198 Hongqi Road, Huzhou, Zhejiang 313000, P.R. China

E-mail:zgy0087@sina.com

Key words: cutoff, colorectal cancer, Ki67, prognosis, AJCC-8
( $\mathrm{P}=0.030$, all others $\mathrm{P}<0.001)$. In conclusion, a cutoff of $25 \%$ for Ki67 expression is a good classification tool. High Ki67 has a close association with poor prognosis in colorectal cancer and independently predicts prognosis in the AJCC-8 stratification.

\section{Introduction}

The incidence and mortality rates of colorectal cancer (CRC) vary around the world $(1,2)$. Early stage CRC commonly shows limited clinical signs, and patients are often diagnosed at the metastatic stage, rendering therapy difficult (3). Therefore, early diagnosis and treatment of CRC remains challenging for patients and surgeons. In 2016, CRC ranked fourth and second among the most frequently diagnosed and the deadliest malignancies, respectively, in the USA (4-7). According to the American Cancer Society, there were approximately 13,450 newly diagnosed cancer patients in the US in 2016, $30 \%$ of whom presented with CRC (8). In 2015, 376,000 new CRC cases were diagnosed in China, with 191,000 succumbing to the malignancy (9). National polyp screening programs constitute an early diagnosis tool, which can markedly improve CRC prognosis (10-14). Early diagnosis and treatment of CRC is becoming increasingly important to surgeons. Surgery remains the principal therapeutic option for loco-regional CRC. At present, robotic and laparoscopic surgeries are performed for CRC, with improve patient outcome in comparison with traditional surgical techniques (15-17). However, patient prognosis is not significantly enhanced. In order to improve the prognosis of CRC patients, surgeons and pathologists have made unremitting efforts to examine the prognostic values of various tumor markers. The American Joint Committee on Cancer (AJCC) tumor-node-metastasis (TNM) staging system provides a universal modality and guides clinical treatment (18-21). Based on the original version, AJCC-8 (American Joint Committee on Cancer 8 edition) provides improved guidance for the individualized treatment of CRC patients and more effective treatment of patients with IVC peritoneal metastases.

Tumor invasion and metastasis of CRC result from well-coordinated events involving many intracellular and extracellular factors (22-24). While many factors affect 
prognosis in CRC $(25,26)$, Ki67 is broadly employed in pathological analyses to evaluate cell proliferation in various malignancies (27-30). Although Ki67 is expressed in benign tumors, its levels are very low; however, it is found at high levels in multiple malignant lesions, and tightly associated with distant metastasis, resulting in poor patient prognosis. The prognostic value of Ki67 has been assessed in various types of cancers, particularly brain, neuroendocrine, and lymphoid tissue malignancies, and its levels are commonly utilized to grade tumors (31). Nevertheless, its prognostic and predictive roles remain debatable mostly as standard quantification techniques for Ki67 are in existence (32). Ki67 expression is usually examined as a percentage, which is closely related to the pathologist's clinical experience.

Hashimoto et al assessed the rate and clinical significance of fascin expression in association with CRC progression and cancer cell proliferation based on Ki67 (33). Most often, Ki67 is assessed visually by pathologists although no consensus is available concerning the specific regions to score (34). Meanwhile, whether automated techniques could yield suitable accuracy and prognostic power for $\mathrm{Ki} 67$ is not known. Indeed, head-to-head comparisons between scores from automated and pathologist-based techniques in terms of prognostic value have been rarely reported, and discrepant findings in breast cancer have been obtained (35-37). Previous reports $(38,39)$ discussed the role of Ki67 expression in lung and breast cancers, examining ways to define the cutoff of Ki67 expression. Similar questions remain for CRC. How to grade Ki67 expression remains therefore an open question. A $20 \%$ cutoff has been reported (38). Nonetheless, a previous meta-analysis assessing various cut-off levels of Ki67 in regards to prognosis suggested a visual cut-off $>25 \%$ to provide a higher discriminatory power in mortality risk compared with the remaining cut-off points evaluated (39). Signal intensity scores were 0 (negative), 1 (weak), 2 (moderate) and 3 (strong); positivity extent was scored as $0(<5 \%), 1(5-25 \%), 2(>25-50 \%, 3$ $(<50-75 \%)$ and $4(>75 \%)$. Both sub-scores were multiplied to yield the final score, which was considered to be positive if $>5$ (40). Can a suitable cutoff increase the prognostic value of Ki67 expression in colorectal cancer? This is the starting point of the present research; as not many studies have been reported. Some scholars hold opposite views on the relationship between Ki67 expression and prognosis in CRC, suggesting that high Ki67 expression instead reflects better prognosis (41). Other studies have reported that mean Ki67 expression is higher in p53-positive cases, and Ki67 and p53 are not correlated to clinical and pathological parameters (42). Whether Ki67 expression is related to clinicopathological indicators and prognosis remains controversial. Meanwhile, the cutoffs vary, and the outcomes are rather controversial among previous studies. Therefore, we analyzed the associations of Ki67 expression with clinicopathological parameters and the prognosis of CRC patients in this study.

Here we divided cases into four grades based on 25\% intervals of Ki67 immunohistochemical signals. Associations of Ki67 expression levels with clinicopathological factors and CRC prognosis were analyzed. Prognosis in CRC was also analyzed based on Ki67 expression according to 5-year disease-free survival (DFS) and overall survival (OS) in and out of the AJCC-8 stratification.

\section{Patients and methods}

Patients. In total, 2,080 CRC cases were enrolled at Huzhou Central Hospital between January 2006 and December 2012. A total of 400 cases did not undergo surgery, 400 succumbed to non-CRC causes, and 190 were lost to follow-up and thus were excluded from the present study. Therefore, 1,090 cases (stage 0 to stage IV) were involved in the final analysis. Inclusion criteria were CRC diagnosis by colonoscopy, computed tomography and pathology; no pre-surgical adjuvant therapy, radical surgery and normal lymph nodes harvested; other organ metastases found before or during surgery, and combined resection to achieve R0 resection; complete postoperative clinical and pathological data; postoperative routine immunohistochemical and pathological analyses; post-surgical chemotherapy based on the National Comprehensive Cancer Network (NCCN) guidelines; adenocarcinoma by pathological diagnosis; complete follow-up data, including recurrence and metastasis at follow-up. Exclusion criteria included severe heart, brain, liver or lung disease which may influence tolerance to surgery; non-CRC parameters causing death, interstitial or neuronal tumor, lymphoma, melanoma and other non-adenocarcinomas concomitant with CRC (Fig. 1).

Follow-up. Routine follow-up was carried out in the outpatient clinic two weeks post-operation, at 3- and 6-month intervals for the first and second years, respectively, and yearly for the remaining 3 years. Phone calls and mail were also used for follow-up. During the follow-up period, the patient statuses included i) death, censored and ii) death and recurrence and censored.

Ethics statement. The current trial followed the 2008 Declaration of Helsinki, and had approval from the Ethics Committee of Huzhou Central Hospital (Huzhou, Zhejiang, China). All patients provided signed informed consent for the use of their tissue samples for Ki67 immunohistochemistry immunoassay and medical records for research.

Detection of tissue Ki67. Immunohistochemistry was performed by the Envision two-step method [cat. no. ZM-0166 (Beijing Zhongshang Jinqiao Co.); K5007 (Dako)]. The primary antibody was raised against Ki67 (cat. no. ZM-0166, 1:200 dilution) and K5007 (Dako; no dilution) was used as the secondary antibody. The steps included: i) Dewaxing with hot water; ii) antigen repair under high pressure citric with acid at $\mathrm{pH} 6.0$; iii) hydrogen peroxide blocking of endogenous peroxidase; iv) primary antibody incubation at $37^{\circ} \mathrm{C}$ for $30 \mathrm{~min}$; v) secondary antibody incubation at $37^{\circ} \mathrm{C}$ for $15 \mathrm{~min}$; vi) $\mathrm{DAB}$ staining at $22^{\circ} \mathrm{C}$ for $5 \mathrm{~min}$; vii) dehydration and mounting. We compared conventional hematoxylin and eosin (H\&E) staining with Ki67 DBA immunostaining and defined + as $>0$ and $\leq 25 \%$; ++ as $>25$ and $\leq 50 \%$; +++ as $>50$ and $\leq 75 \%$; and ++++ as $>75 \%$ (Fig. 2).

Surgical methods. According to lesion location and the principle of malignant tumor resection, the following resection methods were used: Right hemicolectomy (RHC); left hemicolectomy specimen (LHC), with the excised portion 


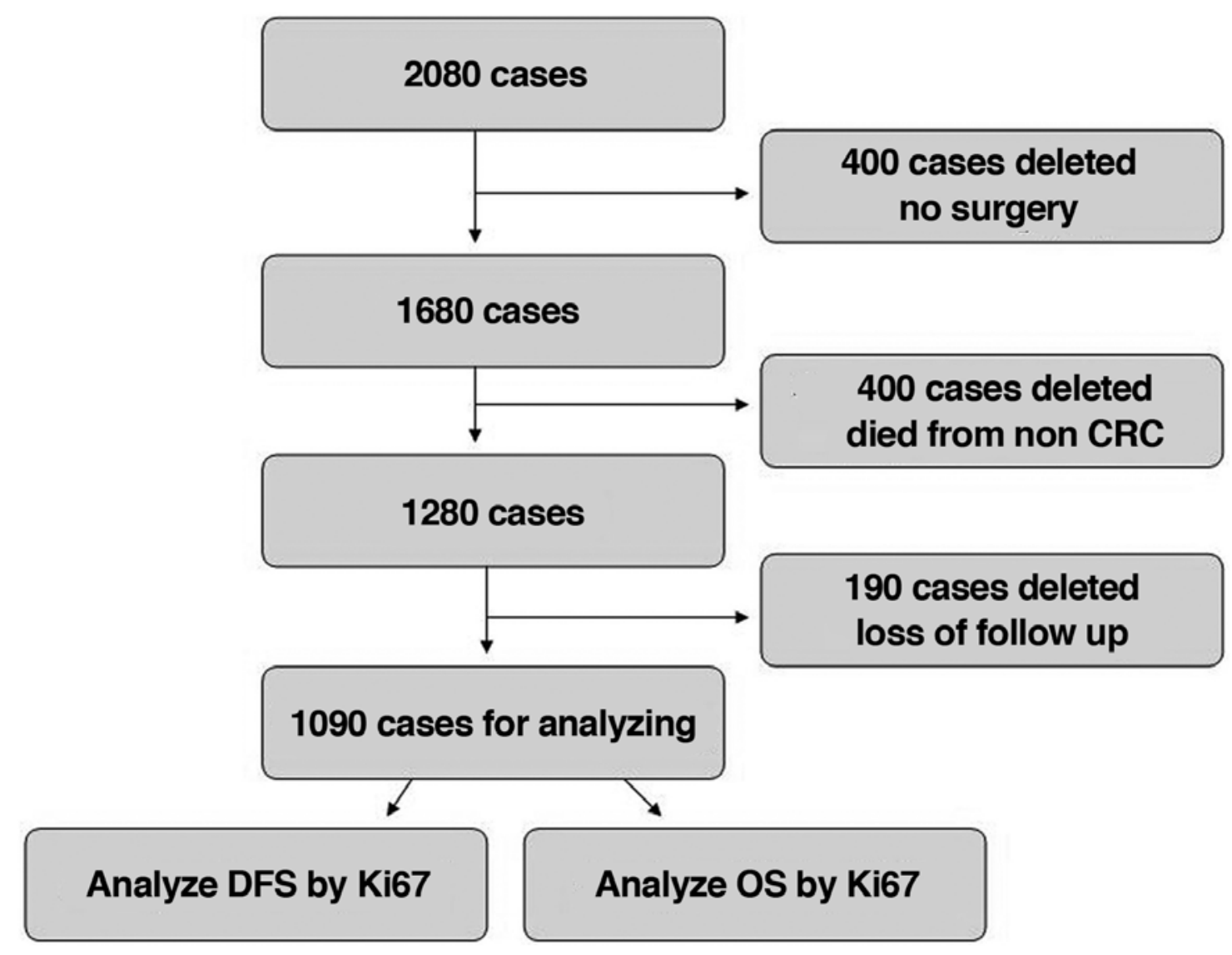

Figure 1. Study flowchart, showing inclusion and exclusion criteria of the CRC cases. CRC, colorectal cancer; DFS, disease-free survival; OS, overall survival.

including the left colon and the descending colon; Hartmann (HO), with $5 \mathrm{~cm}$ tissue distal to the tumor removed and the distal colorectal segment closed, the proximal end removed $(10 \mathrm{~cm})$, and the proximal end taken for fistula; anterior rectal resection specimen (AR), with the extent of resection involving the sigmoid colon and part of the rectum; anterior rectal perineal resection specimen (APR), with the scope of resection involving the sigmoid colon, whole rectum and anal canal and perineum.

Statistical analysis. SPSS 21.0 (IBM Corp.) was employed for data analysis. Clinicopathological measurement data among groups with different Ki67 expression patterns were assessed by one-way analysis of variance (ANOVA); count data were analyzed by Crosstabs and the Pearson's $\chi^{2}$ test. Bivariate correlation analysis was performed to assess clinical and pathological indicators with significant significance in Ki67 expression. Five-year DFS and OS were analyzed by the Kaplan-Meier method and the Breslow test. Survival rates were equally assessed by multivariable Cox's regression according to various clinical, pathological, and biochemical parameters, which were analyzed in our previous studies $(21,26)$. Patient statuses were divided into two: i) Only death was considered an event, and other parameters were censored for OS analysis; ii) death and recurrence were considered events, and other parameters were censored for DFS analysis. Weighted analysis and the non-parametric Chi-square test were applied to compare DFS and OS under different Ki67 levels.

\section{Results}

General data. A total of 1,090 patients of the 2,080 enrolled CRC cases were evaluated (52.4\%), including 550 men $(50.5 \%)$ and 540 women (49.5\%). According to Ki67 expression (+, ++, +++ and ++++$)$, the entire patient population consisted of 61 (11.1\%), 141 (25.6\%), 202 (36.7\%) and $146(26.5 \%)$ male patients, and $70(13 \%), 144(26.7 \%), 195$ (36.1\%) and 131 (24.3\%) females, respectively. The mean age was 62.26 years (range, 17-89).

Clinicopathological properties of the various groups based on Ki67 expression. According to Ki67 expression (from low to high), sex, age, American Society of Anesthesiologists (ASA) stage, location, surgical method, operation time, invasive depth, tumor differentiation, tumor size, AJCC-8 stage, the number of lymph nodes harvested, the number of positive lymph nodes, complications, and chemotherapy status were assessed. By single factor ANONA and F test, there were no significant differences in age, operation time and the number of lymph nodes harvested. However, there were significant differences noted in regards to tumor size and the number of positive lymph nodes. Regarding measurement variations, from Ki67+ to $\mathrm{Ki} 67++++$, mean and standard deviations were as follows: Age, 61.64 $\pm 15.80,62.79 \pm 14.33,62.21 \pm 14.28$ and $62.07 \pm 14.31$ $(\mathrm{P}=0.880)$; operation time (min), 153.6 $\pm 34.8,151.2 \pm 38.6$, $155.0 \pm 33.2$ and $154.1 \pm 33.2(\mathrm{P}=0.568)$; number of lymph nodes harvested, $14.04 \pm 1.9,14.17 \pm 1.8,14.25 \pm 1.8$ and $14.19 \pm 1.9$ $(\mathrm{P}=0.727)$; tumor size $(\mathrm{cm}), 3.58 \pm 1.1,3.38 \pm 1.2,3.74 \pm 0.9$ and $3.79 \pm 0.9(\mathrm{P}<0.001)$; number of positive lymph nodes, $0.25 \pm 0.9$, 
Table I. Association of the clinicopathological features and Ki67 expression in all involved CRC cases.

\begin{tabular}{|c|c|c|c|c|c|c|}
\hline & $\mathrm{N}$ & Ki67+ & Ki67++ & Ki67+++ & Ki67++++ & P-value \\
\hline Sex, n (\%) & & & & & & 0.684 \\
\hline Male & 550 & $61(46.6)$ & $141(49.5)$ & $202(50.9)$ & $146(52.7)$ & \\
\hline Female & 540 & $70(53.4)$ & $144(50.5)$ & $195(49.1)$ & $131(47.3)$ & \\
\hline Mean age (years) & 1,090 & $61.64 \pm 15.80$ & $62.79 \pm 14.33$ & $62.21 \pm 14.28$ & $62.07 \pm 14.31$ & 0.880 \\
\hline ASA stage, n (\%) & & & & & & 0.860 \\
\hline I & 797 & $94(71.8)$ & $212(74.4)$ & $293(73.8)$ & $198(71.3)$ & \\
\hline II & 264 & $33(25.2)$ & $64(22.5)$ & $93(23.4)$ & $74(26.7)$ & \\
\hline III & 29 & $4(3.1)$ & $9(3.2)$ & $11(2.8)$ & $5(1.8)$ & \\
\hline Location, n (\%) & & & & & & 0.439 \\
\hline Ileocecum & 73 & $11(8.4)$ & $20(7.0)$ & $24(6.0)$ & $18(6.5)$ & \\
\hline Right colon & 95 & $4(3.1)$ & $31(10.9)$ & $41(10.3)$ & $19(6.9)$ & \\
\hline Transverse colon & 174 & $25(19.1)$ & $42(14.7)$ & $60(15.1)$ & $47(17.0)$ & \\
\hline Left colon & 206 & $24(18.3)$ & $57(20.0)$ & $75(18.9)$ & $50(18.1)$ & \\
\hline Sigmoid colon & 108 & $16(12.2)$ & $20(7.0)$ & $40(10.1)$ & $32(11.6)$ & \\
\hline Rectum & 434 & $51(38.9)$ & $115(40.4)$ & $157(39.5)$ & $111(40.1)$ & \\
\hline Surgical method, n (\%) & & & & & & 0.768 \\
\hline RHC & 207 & $21(16.0)$ & $58(20.4)$ & $80(20.2)$ & $48(17.3)$ & \\
\hline LHC & 431 & $55(42.0)$ & $108(37.9)$ & $155(39.0)$ & $113(40.8)$ & \\
\hline $\mathrm{HO}$ & 24 & $3(2.3)$ & $7(2.5)$ & $6(1.5)$ & $8(2.9)$ & \\
\hline AR & 327 & $43(32.8)$ & $91(31.9)$ & $112(28.2)$ & $81(29.2)$ & \\
\hline APR & 101 & $9(6.9)$ & $21(7.4)$ & $44(11.1)$ & $27(9.7)$ & \\
\hline Operation time (min) & 1,090 & $153.6 \pm 34.8$ & $151.2 \pm 38.6$ & $155.0 \pm 33.2$ & $154.1 \pm 33.2$ & 0.568 \\
\hline Invasive depth, n (\%) & & & & & & $<0.001^{\mathrm{a}}$ \\
\hline Tis and $\mathrm{T} 1$ & 127 & $24(18.3)$ & $53(18.6)$ & $31(7.8)$ & $19(6.9)$ & \\
\hline $\mathrm{T} 2$ & 210 & $5(3.8)$ & $66(23.2)$ & $112(28.2)$ & $27(9.7)$ & \\
\hline $\mathrm{T} 3$ & 421 & $78(59.5)$ & $92(32.3)$ & $132(33.2)$ & $119(43.0)$ & \\
\hline $\mathrm{T} 4$ & 332 & $24(18.3)$ & $74(6.0)$ & $122(30.7)$ & $112(40.4)$ & \\
\hline Differentiation, n (\%) & & & & & & $<0.001^{\mathrm{a}}$ \\
\hline Well & 194 & $58(44.3)$ & $97(34.0)$ & $30(7.6)$ & $9(3.2)$ & \\
\hline Moderate & 696 & $69(52.7)$ & $177(62.1)$ & $282(71.0)$ & $168(60.6)$ & \\
\hline $\begin{array}{l}\text { Poor or } \\
\text { undifferentiation }\end{array}$ & 200 & $4(3.1)$ & $11(3.9)$ & $85(21.4)$ & $100(36.1)$ & \\
\hline Tumor size (cm) & 1,090 & $3.58 \pm 1.1$ & $3.38 \pm 1.2$ & $3.74 \pm 0.9$ & $3.79 \pm 0.9$ & $<0.001^{\mathrm{a}}$ \\
\hline AJCC-8 , n (\%) & & & & & & $0.003^{\mathrm{a}}$ \\
\hline 0 & 16 & $5(3.8)$ & $11(3.9)$ & $0(0)$ & $0(0)$ & \\
\hline I & 131 & $17(13.0)$ & $85(29.8)$ & $28(7.1)$ & $1(0.4)$ & \\
\hline II & 225 & $93(71.0)$ & $112(39.3)$ & $12(3.0)$ & $8(2.9)$ & \\
\hline III & 663 & 14 (10.7) & $75(26.3)$ & 323 (81.4) & $25(90.6)$ & \\
\hline IV & 55 & $2(1.5)$ & $2(0.7)$ & $34(8.6)$ & $17(6.1)$ & \\
\hline No. of lymph nodes harvested & 1,090 & $14.04 \pm 1.9$ & $14.17 \pm 1.8$ & $14.25 \pm 1.8$ & $14.19 \pm 1.9$ & 0.727 \\
\hline No of positive lymph nodes & 1,090 & $0.25 \pm 0.9$ & $0.61 \pm 1.4$ & $2.45 \pm 2.2$ & $2.86 \pm 2.5$ & $<0.001^{\mathrm{a}}$ \\
\hline Complications & & & & & & 0.587 \\
\hline Yes & 104 & $13(9.9)$ & $28(9.8)$ & $32(8.1)$ & $31(11.2)$ & \\
\hline No & 986 & $118(90.1)$ & $257(90.2)$ & $365(91.9)$ & $246(88.8)$ & \\
\hline Chemotherapy, n (\%) & & & & & & $0.005^{\mathrm{a}}$ \\
\hline Yes & 895 & $107(81.7)$ & $189(66.3)$ & $343(86.4)$ & $256(92.4)$ & \\
\hline No & 195 & $24(18.3)$ & $96(33.7)$ & $54(13.6)$ & $21(7.6)$ & \\
\hline
\end{tabular}

${ }^{\mathrm{a}} \mathrm{P}<0.05$, statistical difference. Data for age, operation time, tumor size, no. of lymph harvested and no. of positive lymph nodes are expressed as mean \pm standard deviation. CRC, colorectal cancer; AJCC-8, American Joint Committee on Cancer 8 edition; ASS, American Society of Anesthesiologists. Surgical method: RHC, right hemicolectomy; LHC, left hemicolectomy; HO, Hartmann; AR, anterior rectal resection APR, anterior rectal perineal resection. 
H\&E

Ki67
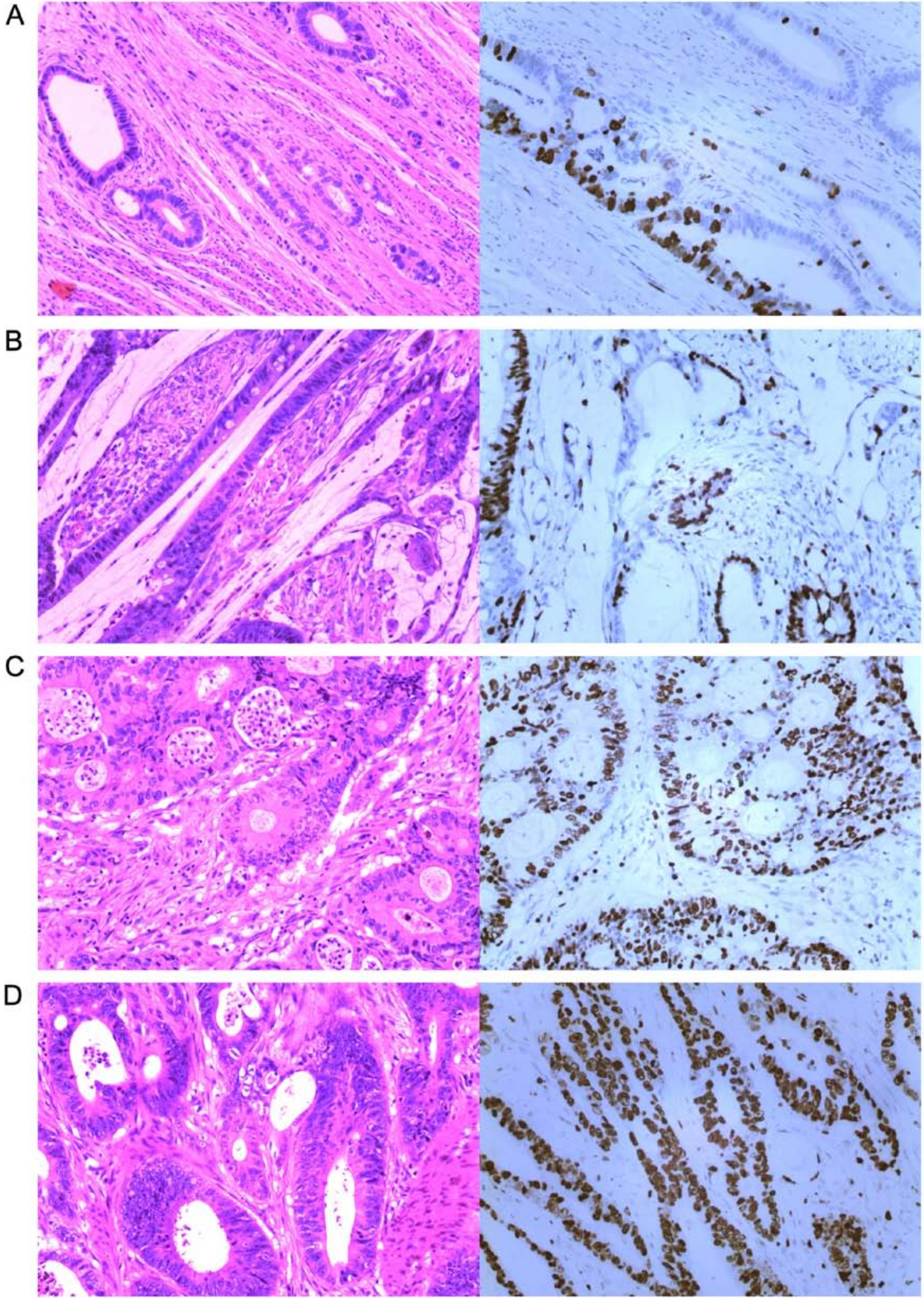

Figure 2. Routine H\&E staining and Ki67 DAB immunohistochemical staining for CRC (magnification, $x 200)$. (A) $\leq 25 \%$ indicating + (this image shows $20 \%$ ). (B) $>25$ and $\leq 50 \%$ indicating ++ (this image shows $30 \%$ ). (C) $>50$ and $\leq 75 \%$ indicating +++ (this image shows $70 \%$ ). (D) $>75 \%$ indicating ++++ (this image shows $90 \%$ ). CRC, colorectal cancer; H\&E, hematoxylin and eosin; DAB, 3,3'-diaminobenzidine.

$0.61 \pm 1.4,2.45 \pm 2.2$ and $2.86 \pm 2.5(\mathrm{P}<0.001)$. From $\mathrm{Ki67}(+)$ to $\mathrm{Ki} 67(++++)$ significant differences were found in count variables such as invasive depth, tumor differentiation, AJCC-8 stage and chemotherapy status $(\mathrm{P}<0.001 ; \mathrm{P}<0.001 ; \mathrm{P}=0.003$ and $\mathrm{P}=0.005$, respectively). However, no statistical differences were found in sex, ASA stage, location, surgical method, and complications $(\mathrm{P}=0.684, \mathrm{P}=0.860, \mathrm{P}=0.439, \mathrm{P}=0.768$ and $\mathrm{P}=0.587$, respectively). Details are shown in Table I. 
Table II. Significant correlations between Ki67 and clinicopathological features of the CRC cases.

\begin{tabular}{lccc}
\hline Ki67 & $\begin{array}{c}\text { Spearman } \\
\text { rho }\end{array}$ & $\begin{array}{c}95 \% \text { CI } \\
\text { (lower-upper) }\end{array}$ & P-value \\
\hline Invasive depth & 0.170 & $0.113-0.225$ & $<0.001^{\mathrm{a}}$ \\
Tumor differentiation & 0.456 & $0.411-0.500$ & $<0.001^{\mathrm{a}}$ \\
Tumor size & 0.122 & $-0.063-0.181$ & $<0.001^{\mathrm{a}}$ \\
AJCC-8 stage & 0.195 & $0.138-0.254$ & $<0.001^{\mathrm{a}}$ \\
No of positive lymph & 0.514 & $0.468-0.558$ & $<0.001^{\mathrm{a}}$ \\
nodes & & & \\
Chemotherapy status & -0.201 & $-0.253-0.148$ & $<0.001^{\mathrm{a}}$ \\
\hline
\end{tabular}

${ }^{a}$ Correlation is significant at 0.05 . CRC, colorectal cancer; CI, confidence interval AJCC-8, American Joint Committee on Cancer 8 edition.

Associations of Ki67 with clinicopathological features showing significant differences. We further analyzed the associations of clinicopathological indices which showed significant differences based on Ki67 expression. Spearman rho coefficients of invasive depth, tumor differentiation, tumor size, AJCC- 8 stage, the number of positive lymph nodes and chemotherapy status were 0.170 (95\% CI $0.113-0.225$, $\mathrm{P}<0.001), 0.456$ (95\% CI 0.411-0.500, $\mathrm{P}<0.001), 0.122(95 \% \mathrm{CI}$ -0.063-0.181, $\mathrm{P}<0.001), 0.195$ (95\% CI 0.138-0.254, $\mathrm{P}<0.001$ ), 0.514 (95\% CI 0.468-0.558) and -0.201 (95\% CI -0.253-0.148, $\mathrm{P}<0.001)$, respectively, as summarized in Table II.

Five-year DFS and OS by Ki67 expression in AJCC-8 stratification. The Kaplan-Meier method and Breslow test were applied to assess DFS and OS based on Ki67 expression in the AJCC-8 stratification. There were significant differences in DFS among the various Ki67 expression groups from AJCC-8=I to AJCC-8=III (all $\mathrm{P}<0.001$ ), but no statistical significance at AJCC-8 $=\mathrm{IV}(\mathrm{P}=0.334$; Fig. 3A-D). There were significant differences in $\mathrm{OS}$ among the different $\mathrm{Ki} 67$ expression groups from AJCC-8=I to AJCC-8=III (all $\mathrm{P}<0.001$ ), but no statistical significance at AJCC-8=IV $(\mathrm{P}=0.334$; Fig. 4A-D). DFS and OS survival rates were assessed based on Ki67 expression and AJCC- 8 stratification. Table III documents the DFS and OS survival rates at different Ki67 levels in the AJCC-8 stratification. There were no patients with $\mathrm{Ki} 67+++$ or Ki67++++ at stage 0, not only in DFS but also in OS. Table IV shows a comparison of DFS and OS at different Ki67 expression levels. There were no significant differences among all columns $\left(\chi^{2}=0.202, \mathrm{P}=0.653 ; \chi^{2}=0.098, \mathrm{P}=0.755\right.$; $\chi^{2}=0.136, \mathrm{P}=0.713$ and $\chi^{2}=0.211 \mathrm{P}=0.646$ respectively). DFS and OS showed statistical differences only between Ki67 expression groups (Breslow=164.66, $\mathrm{P}<0.001$; Brelow=166.79, $\mathrm{P}<0.001$ ), indicating elevated Ki67 expression was associated with poorer prognosis. Details are shown in Table IV and Fig. 5A and B. Crosstabs analysis showed that there were no significant differences between DFS and OS at different Ki67 expression levels $\left(\chi^{2}=0.041, \mathrm{P}=0.098\right.$; Fig. 5C).

Multivariable analysis of CRC prognostic factors. To identify independent predictive factors of CRC prognosis, Cox propor-
Table III. Analysis of the 5-year DFS and OS by Ki67 expression according to AJCC-8 stage.

\begin{tabular}{ccccccc}
\hline & & $\mathrm{N}$ & + & ++ & +++ & ++++ \\
\hline DFS & 0 & 16 & 100 & 100 & - & - \\
& I & 131 & 88.2 & 94.1 & 96.4 & 0 \\
& II & 225 & 90.3 & 72.3 & 25.0 & 0 \\
& III & 663 & 64.3 & 73.3 & 61.0 & 39.8 \\
& IV & 55 & 0 & 0 & 0 & 0 \\
OS & 0 & 16 & 100 & 100 & - & - \\
& I & 131 & 94.1 & 100 & 100 & 0 \\
& II & 225 & 96.8 & 75.9 & 25.0 & 0 \\
& III & 663 & 64.3 & 77.3 & 64.4 & 44.2 \\
& IV & 55 & 0 & 0 & 5.9 & 0 \\
\hline
\end{tabular}

-, no case of Ki67 expression. AJCC-8, American Joint Committee on Cancer 8 edition; DFS, disease-free survival; OS, overall survival. Data expressed as a percentage $(\%)$.

tional hazard model analysis was performed. Sex, invasive depth, lymph node metastasis, tumor differentiation, AJCC-8 stage, chemotherapy status and Ki67 were included in the model. Regarding sex and chemotherapy status, hazard ratios (HRs) (95\% CIs) for Female/Male and No/Yes were 0.976 (0.796-1.198) and 0.986 (0.522-1.862), respectively, which were not significant $(\mathrm{P}=0.819$ and $\mathrm{P}=0.964$, respectively). HRs (95\% CIs) for invasive depth at T2/Tis and T1, T3/Tis and T1, $\mathrm{T} 4 / \mathrm{Tis}$ and $\mathrm{T} 1$ were 1.5336 (0.855-2.748), 1.845 (1.034-3.290) and 1.331 (0.746-2.376), respectively, showing statistically significant differences $(\mathrm{P}=0.03)$. HRs $(95 \% \mathrm{CIs})$ for lymph node metastasis at N1/N0 and N2/N0 were 0.909 (0.616-1.342) and $1.690(1.168-2.446)(\mathrm{P}<0.001)$. Regarding differentiation (moderate/well, poor or no/well), AJCC-8 stage (I/0, II/0, III/0 and IV/0), Ki67 expression $(++/+,+++/+$ and $++++/+)$ HRs (95\% CIs) were, respectively, 1.677 (1.036-2.715), $6.443(3.883-10.756)$ and $134.375(0-1.173 \mathrm{E}+29) ; 2,015.297$ $(0-1.736 \mathrm{E}+30), 1,098.443(0-9.461 \mathrm{E}+30)$ and 30582.466 $(0-2.637 \mathrm{E}+31)$; and 2.59 (1.327-50055), 4.732 (2.275-9.843) and $6.762(3.226-14.174)$, showing significant differences (all $\mathrm{P}<0.001$; Table V).

\section{Discussion}

In the present study, we initially considered whether to include stage 0. Some Ki67 data were not available in this period, which inevitably resulted in that survival classified by Ki67 was not calculated. According to AJCC-8 (American Joint Committee on Cancer 5th edition) and later versions, colorectal cancer CRC) stage 0 refers to TisN0M0. This refers to carcinoma in situ, which is localized within the epithelium or infiltrates the lamina propria. Although it is not invasive cancer, it is invasive. We believe that stage 0 tumors are within the mucosa, but not invasive malignant tumors because invasive malignancies usually refer to advanced cancer. Therefore, we included stage 0 in this study. With the increasing attention paid to early CRC detection, this study found that stages 0 -II only accounted 
Table IV. Comparison of the 5-year DFS and OS by Ki67 expression (\%).

\begin{tabular}{lcccccr}
\hline & $\mathrm{N}$ & + & ++ & +++ & ++++ & Breslow \\
\hline DFS & 1,090 & 86.3 & 79.6 & 57.2 & 36.1 & 164.66 \\
OS & 1,090 & 91.6 & 83.9 & 60.7 & 40.1 & 166.79 \\
$\chi^{2}$ & & 0.202 & 0.098 & 0.136 & 0.211 & $<0.001$ \\
P-value & & 0.653 & 0.755 & 0.713 & 0.646 & \\
\hline
\end{tabular}

DFS, disease-free survival; OS, overall survival. Data are expressed as a percentage (\%).

A

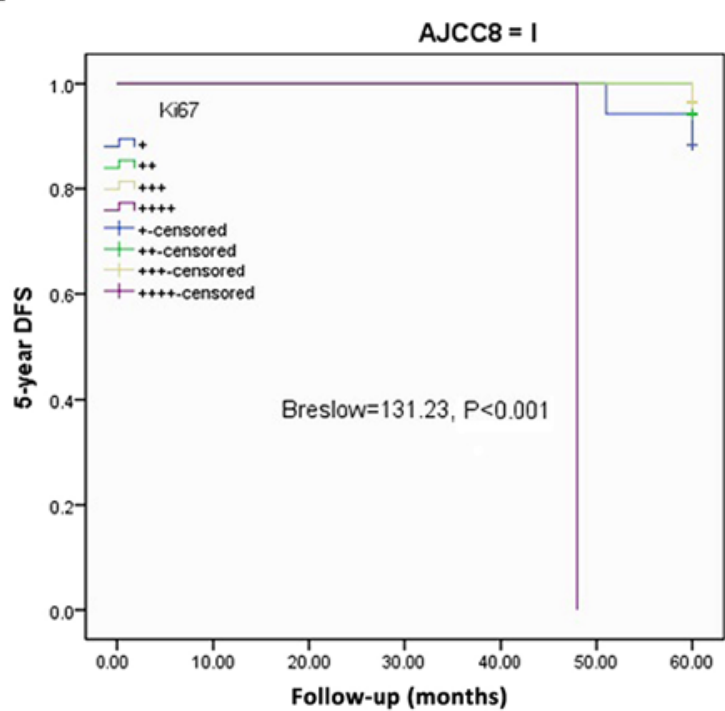

C

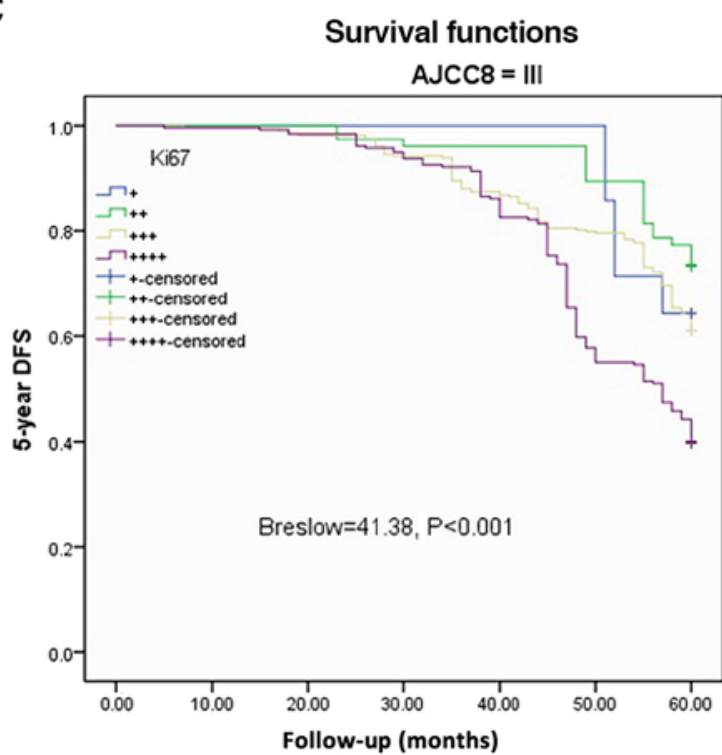

B

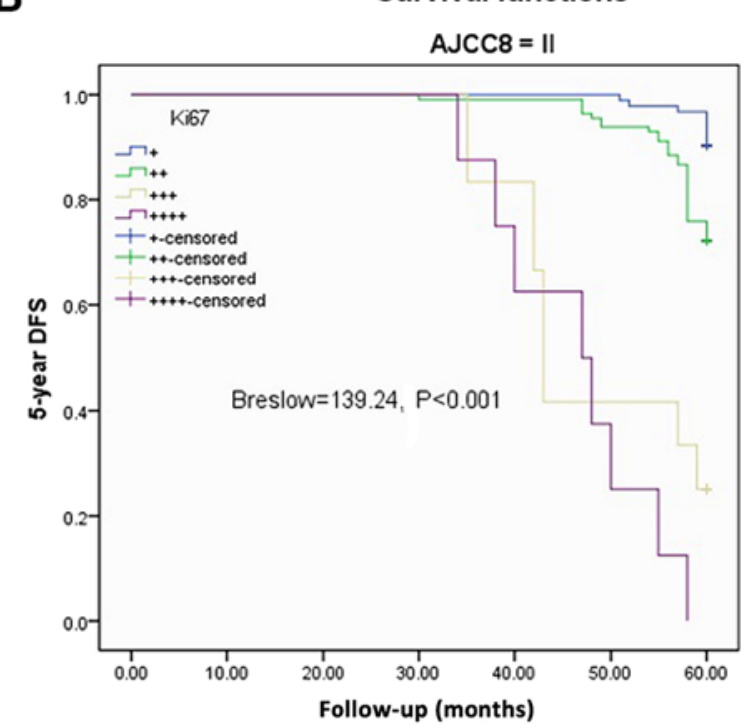

D

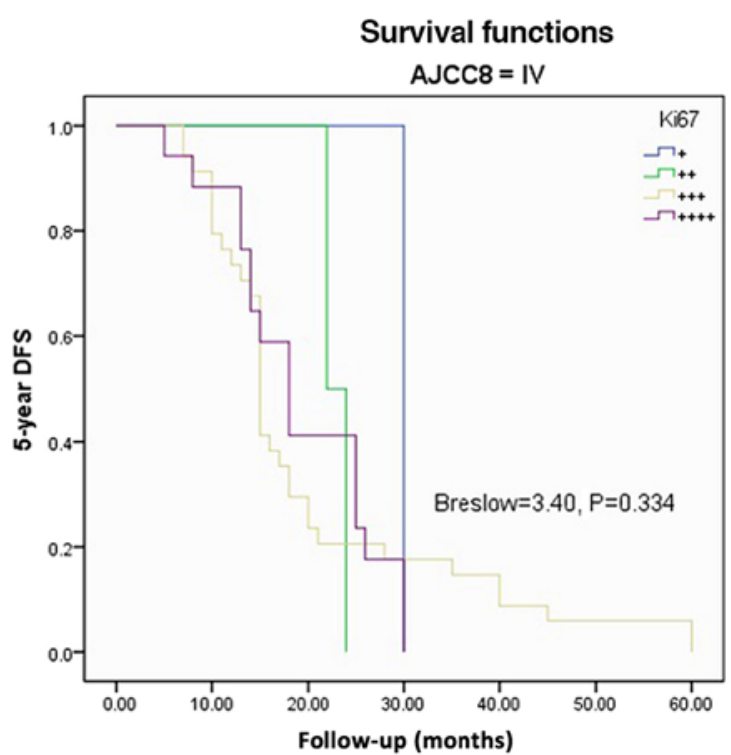

Figure 3. Disease-free survival (DFS) based on different Ki67 expression levels according to AJCC-8 stratification. (A) 5-year DFS in stage I (Breslow=131.23, $\mathrm{P}<0.001$ ). (B) 5-year DFS in stage II (Breslow=139.24, $\mathrm{P}<0.001$ ). (C) 5-year DFS in stage III (Breslow=41.38, $\mathrm{P}<0.001$ ). (D) 5-year DFS in stage IV (Breslow=3.40, $\mathrm{P}=0.334)$. AJCC-8, American Joint Committee on Cancer 8 edition.

for $34.12 \%$ of all cases, and most cases were stage III in the same period, accounting for $60 \%$. Therefore, the diagnosis and treatment of CRC still requires further investigation to improve prognosis. As published in previous reports (10-14), national polyp screening programs could improve CRC prognosis drastically. Research and application of many tumor markers improve the early detection rate of tumors as well as patient prognosis (43-45). Ki67 expression is a 
Table V. Multivariate analysis of prognosis for CRC using OS.

\begin{tabular}{|c|c|c|}
\hline Factors & HR $(95 \% \mathrm{CI})$ & P-value \\
\hline Sex & & 0.819 \\
\hline Female/Male & $0.976(0.796-1.198)$ & \\
\hline Invasive depth & & $0.030^{\mathrm{a}}$ \\
\hline $\mathrm{T} 2 / \mathrm{Tis}$ andT1 & $1.5336(0.855-2.748)$ & \\
\hline $\mathrm{T} 3 / \mathrm{Tis}$ and $\mathrm{T} 1$ & $1.845(1.034-3.290)$ & \\
\hline $\mathrm{T} 4 / \mathrm{Tis}$ and $\mathrm{T} 1$ & $1.331(0.746-2.376)$ & \\
\hline Lymph node metastasis & & $<0.001^{\mathrm{a}}$ \\
\hline N1/N0 & $0.909(0.616-1.342)$ & \\
\hline N2/N0 & $1.690(1.168-2.446)$ & \\
\hline Differentiation & & $<0.001^{\mathrm{a}}$ \\
\hline Moderate/well & $1.677(1.036-2.715)$ & \\
\hline Poorly or undifferentiation/well & $6.443(3.883-10.756)$ & \\
\hline AJCC-8 stage & & $<0.001^{\mathrm{a}}$ \\
\hline $\mathrm{I} / 0$ & $134.375(0-1.173 \mathrm{E}+29)$ & \\
\hline $\mathrm{II} / 0$ & $2,015.297(0-1.736 \mathrm{E}+30)$ & \\
\hline $\mathrm{III} / 0$ & $1,098.443(0-9.461 \mathrm{E}+30)$ & \\
\hline $\mathrm{IV} / 0$ & $3,0582.466(0-2.637 \mathrm{E}+31)$ & \\
\hline Chemotherapy status & & 0.964 \\
\hline $\mathrm{No} / \mathrm{Yes}$ & $0.986(0.522-1.862)$ & \\
\hline Ki67 & & $<0.001^{\mathrm{a}}$ \\
\hline$++/+$ & $2.59(1.327-50055)$ & \\
\hline$+++/+$ & $4.732(2.275-9.843)$ & \\
\hline$++++/+$ & $6.762(3.226-14.174)$ & \\
\hline
\end{tabular}

${ }^{\mathrm{a}} \mathrm{P}<0.05$ Statistical significant. CRC, colorectal cancer; OS, overall survival; HR, hazard ratio; CI, confidence interval; AJCC-8, American Joint Committee on Cancer 8 edition.

tumor marker that has been used for a long time in clinical practice, but its classification criteria and relationship with prognosis remain controversial $(39,46,47)$. What role does Ki67 expression play in the prognosis of colorectal cancer? Melling et al (41) considered that high Ki67 has a good prognostic value for CRC, contrasting with Luo et al (40). Their results showed that high $\mathrm{Ki67}$ expression is associated with low tumor stage and nodal status, but not with tumor grade, histological tumor type or tumor localization, representing an independent predictor of favorable survival; these findings strongly argue for a clinical utility of Ki67 immunostaining as an independent prognostic biomarker in CRC. This study showed that high Ki67 expression was associated not only with tumor stage (AJCC-8), tumor size and nodal status, but also with tumor differentiation, tumor invasive depth, and chemotherapy status, which were not discussed in Meling et al (41). We used 25\% as a cutoff for Ki67 expression and different study methods such as in and out AJCC-8 stratification, which may explain the discrepancy. The above findings indicate that it is ideal to use $25 \%$ as a cutoff for Ki67 expression.

The nuclear protein Ki67 was first described in Hodgkin lymphoma-derived cells (48). It is expressed throughout cell division, but is highly suppressed in resting cells (G0 phase) (49,50). Ki67 staining is broadly utilized clinically as an index of cell proliferation, although its functions and dynamics are poorly understood. Miller et al (51) tracked Ki67 amounts in single cells without external stimuli, and demonstrated that it accumulates only in the S, G2, and M phases, with continuous degradation in G1 and G0. Ki67 expression is commonly utilized in oncology as a proliferation indicator. Here we explored the association of Ki67 expression with CRC.

Forones et al (42) hypothesized that Ki67 and P53 are not correlated with clinical and pathologic parameters. This study showed differences in tumor invasive depth based on the Ki67 amounts, and elevated Ki67 expression was associated with increased invasive depth. This may be because tumor invasion and metastasis result from highly coordinated events involving many intracellular and extracellular factors $(18,19)$. Another reason may be that higher $\mathrm{Ki} 67$ amounts are associated with poorer tumor differentiation and high AJCC grade, as well as elevated positive lymph node rate, corroborating this study.

We assessed the associations of clinicopathological features with Ki67 expression, and the results showed strong correlations, which require confirmation by molecular and genetic studies. We also showed that the surgical method was not related to Ki67 expression, demonstrating that cancer location 
A

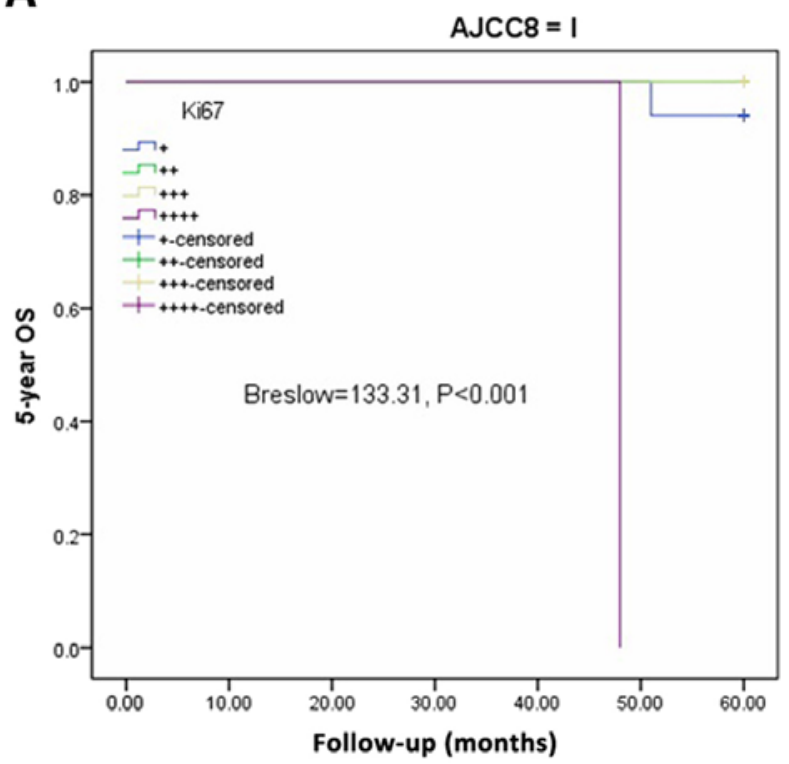

C

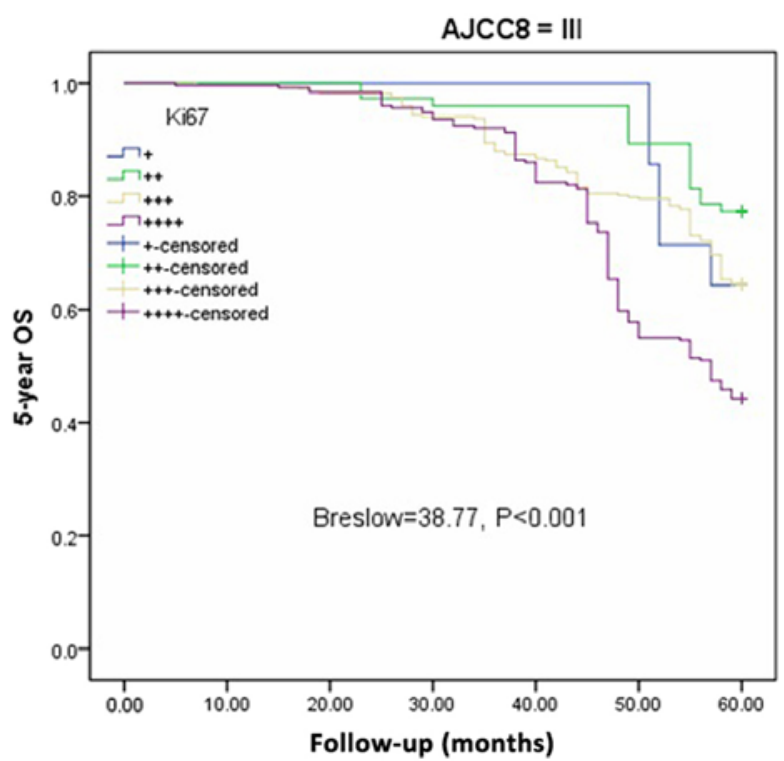

B

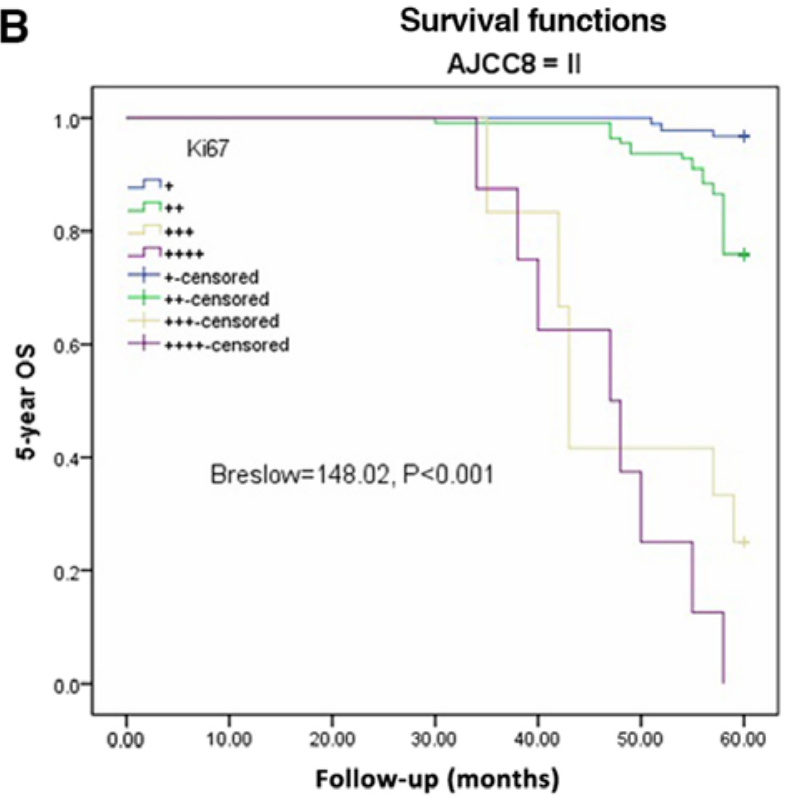

D

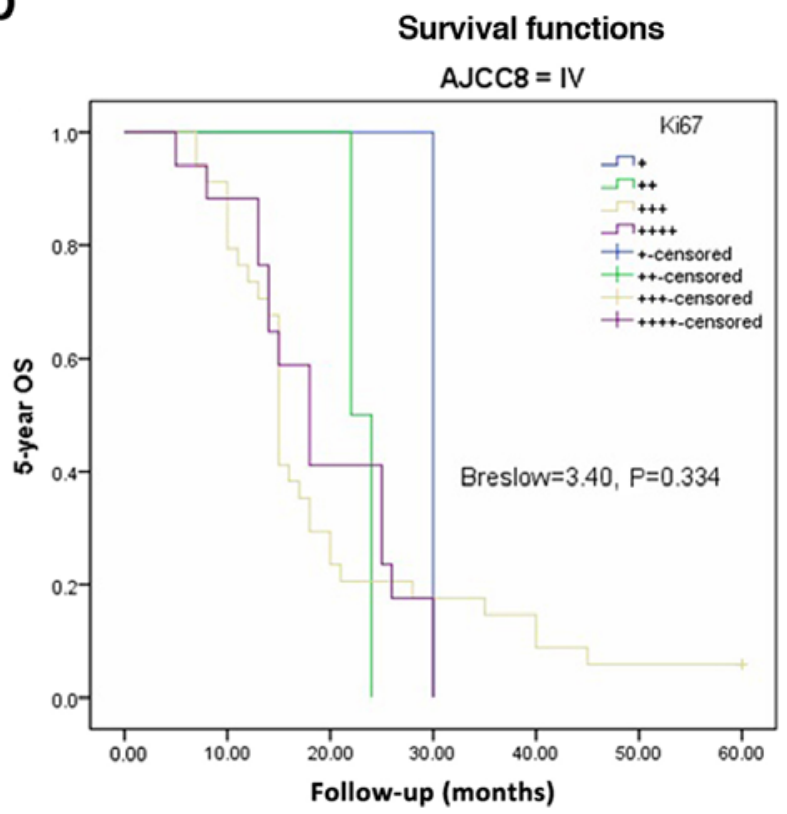

Figure 4. Overall survival (OS) based on different Ki67 expression levels according to AJCC-8 stratification. (A) 5-year OS in stage I (Breslow=133.31, $\mathrm{P}<0.001$ ). (B) 5-year OS in stage II (Breslow=148.02, $\mathrm{P}<0.001$ ). (C) 5-year OS in stage III (Breslow=38.77, $\mathrm{P}<0.001$ ). (D) 5-year OS in stage IV (Breslow=3.40, $\mathrm{P}=0.334)$. AJCC-8, American Joint Committee on Cancer 8 edition.

in CRC is not associated with Ki67 expression. In this study, all tumor cases were adenocarcinomas. The associations of other types of cancer, such as melanoma, carcinoid, malignant stoma tumor and neurofibroma, with Ki67 expression, were not covered in this work. This is a flaw in the present study. We expect relevant studies to be performed.

One of the highlights of this work is that DFS and OS were analyzed based on Ki67 expression in and out of the AJCC-8 stratification. Higher Ki67 expression levels reflected poorer DFS and OS out of the AJCC-8 stratification with statistical significance.

Feng et al (52) reported that elevated Ki67 expression is associated with poorer prognosis in breast cancer. Shin et al (53) pointed out that high Ki67 reflects poor prognosis in CRC.
This suggests that the gene encoding Ki67 has a similar function in tumors. However, it is puzzling that analysis based on the AJCC-8 stratification revealed comparable DFS and OS for different $\mathrm{Ki} 67$ levels in stage IV cases. In general, Ki-67 is closely related to RNA transcription, and shows high expression levels during cell division and proliferation, reflecting the activity of cell division and increasing the risk of tumor invasion and metastasis, which worsen patient prognosis (54). We believe that patients with stage IV disease have poorer prognosis, and adverse factors other than Ki67 expression may play additional roles, such as surgery, chemotherapy, patient physical status, and genetic factors (55-60). In the present study, cases with stage IV disease were limited in number, which could have caused a bias. We look forward to under- 
A

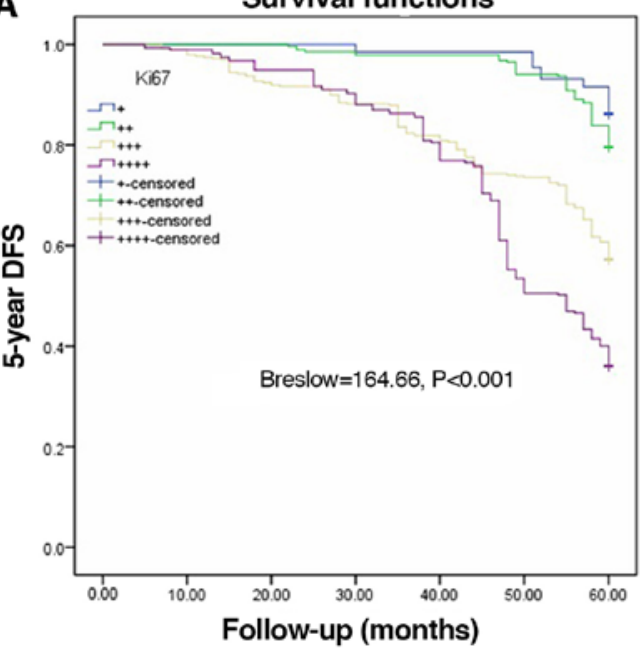

B

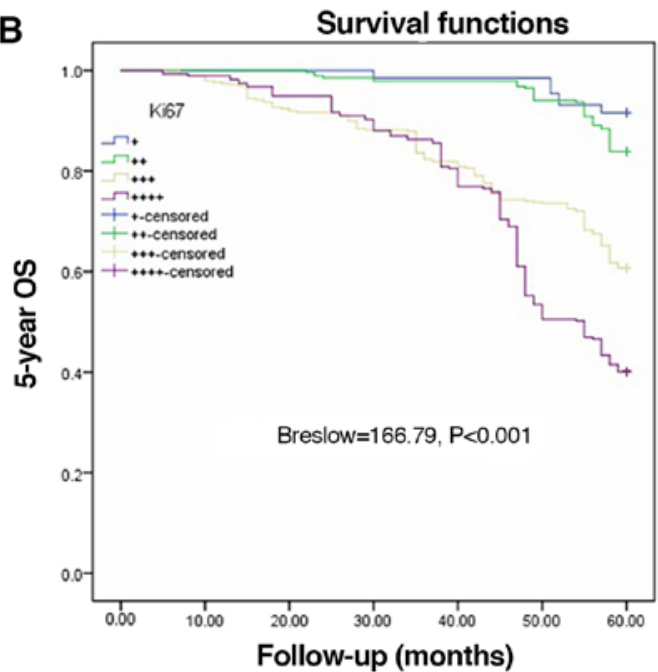

C Bar chart

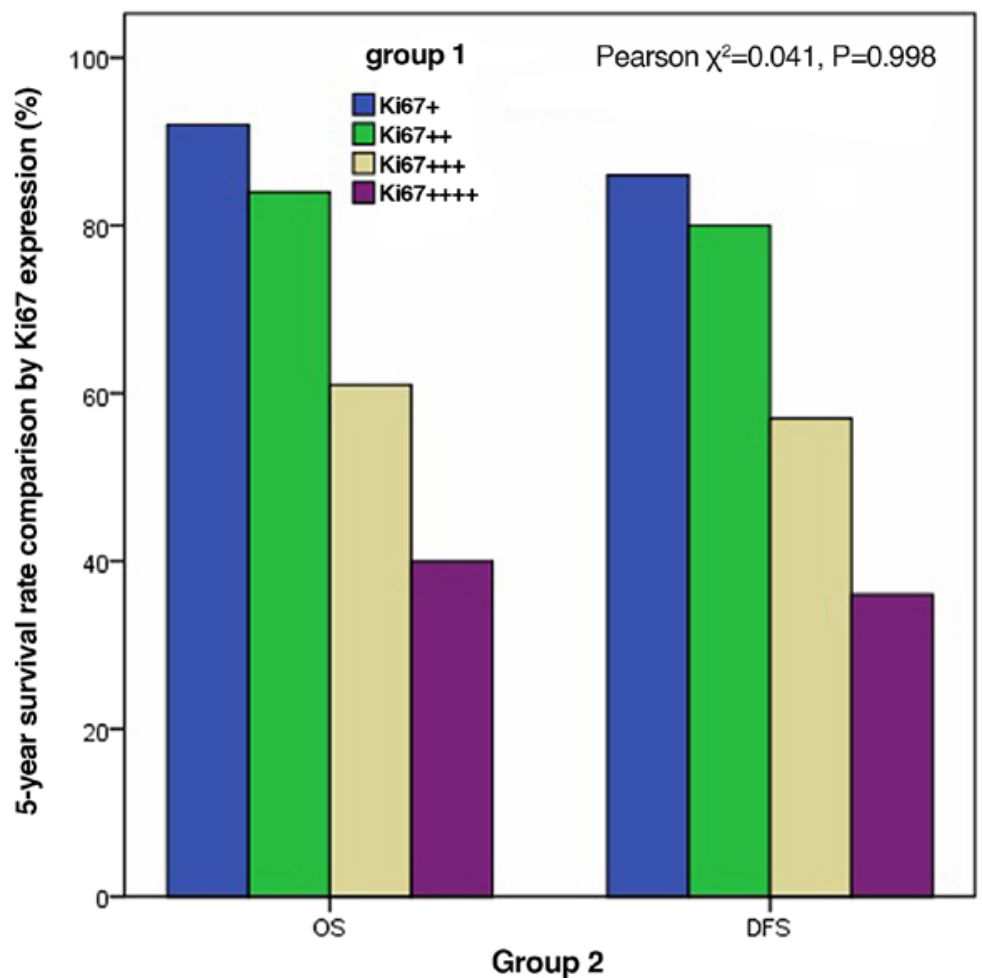

Figure 5. Disease-free survival (DFS) and overall survival (OS) based on different Ki67 expression levels, and comparison of DFS and OS by Ki67 expression out of AJCC-8 stratification. (A) 5-year DFS (Breslow=164.66, $\mathrm{P}<0.001$ ). (B) 5-year OS (Breslow=166.79, $\mathrm{P}<0.001$ ). (C) There was no significant difference between the DFS and OS groups by Ki67 expression $\left(\chi^{2}=0.041, \mathrm{P}=0.998\right)$. AJCC-8, American Joint Committee on Cancer 8 edition.

going future research to assess patients with stage IV CRC and Ki67 expression. Finally, the present study demonstrated that Ki67 expression is an independent risk factor for poor prognosis in CRC by multivariate analysis and Cox regression.

Mucinous vs. non-mucinous lesions have different molecular mechanisms $(61,62)$, but this issue was not investigated in this study. We used the Broder classification of clinicopathological features to analyze Ki67 expression. Some limitations may exist, including no analysis of the marker P53.

In conclusion, a cutoff of $25 \%$ is a good classification tool. In such classification, high Ki67 amounts are closely associ- ated with poor prognosis in CRC and independently predict prognosis in the AJCC-8 stratification.

\section{Acknowledgements}

We are grateful to Professors Liqing Li, Qiang Yan and Zhihong Ma for critically revising this manuscript, as well as to Professor Jingliang Ping and Wei Xu for carrying out the pathological analyses. Trial registration: Chinese Clinical Trial Registry ChiCTR20190404 Registered 4 April 2019 Retrospectively registered http//:www.chictrorgcnindexaspx. 


\section{Funding}

No current external funding sources sponsored this study, which was funded by Project 2018C37090 to GT.

\section{Availability of data and materials}

The corresponding author will provide all data upon reasonable request.

\section{Authors' contributions}

GT, GZ, JL and ZZ conceived and designed the study. GT and YC performed the procedures of data collection and statistical analysis and wrote the initial manuscript. PN and XX were involved in the conception of the study and edited the manuscript. All authors read and approved the final manuscript.

\section{Ethics approval and consent to participate}

The current trial followed the 2008 Declaration of Helsinki, and had approval from the Ethics Committee of Huzhou Central Hospital (Huzhou, Zhejiang, China). All patients provided signed informed consent for the use of their tissue samples for Ki67 immunohistochemistry immunoassay and medical records for research.

\section{Patient consent for publication}

Not applicable.

\section{Competing interests}

All authors declare no competing interests regarding the present study.

\section{References}

1. Torre LA, Bray F, Siegel RL, Ferlay J, Lortet-Tieulent J and Jemal A: Global cancer statistics, 2012. CA Cancer J Clin 65 87-108, 2015.

2. Chen ST, Wu MC, Hsu TC, Yen DW, Chang CN, Hsu WT, Wang CC, Lee M, Liu SH and Lee CC; Health Economics and Outcome Research Group, National Taiwan University Hospital: Comparison of outcome and cost among open, laparoscopic, and robotic surgical treatments for rectal cancer: A propensity score matched analysis of nationwide inpatient sample data. J Surg Oncol 117: 497-505, 2018

3. Siegel R, Naishadham D and Jemal A: Cancer statistics, 2013. CA Cancer J Clin 63: 11-30, 2013.

4. Ali I, Lone MN, Al-Othman ZA, Al-Warthan A and Sanagi MM: Heterocyclic scaffolds: Centrality in anticancer drug development. Curr Drug Targets 16: 711-734, 2015.

5. Ali I, Wani WA, Haque A and Saleem K: Glutamic acid and its derivatives: Candidates for rational design of anticancer drugs. Future Med Chem 5: 961-978, 2013.

6. Ali I, Haque A, Saleem K and Hsieh MF: Curcumin-I Knoevenagel's condensates and their Schiff's bases as anticancer agents: Synthesis, pharmacological and simulation studies. Bioorg Med Chem 21: 3808-3820, 2013

7. Ali I, Wani WA, Saleem K and Haque A: Platinum compounds: A hope for future cancer chemotherapy. Anticancer Agents Med Chem 13: 296-306, 2013.

8. Miller KD, Siegel RL, Lin CC, Mariotto AB, Kramer JL, Rowland JH, Stein KD, Alteri R and Jemal A: Cancer treatment and survivorship statistics, 2016. CA Cancer J Clin 66: 271-289, 2016.
9. Chen W, Zheng R, Baade PD, Zhang S, Zeng H, Bray F, Jemal A, Yu XQ and He J: Cancer statistics in China, 2015. CA Cancer J Clin 66: 115-132, 2016.

10. Buskermolen M, Cenin DR, Helsingen LM, Guyatt G, Vandvik PO, Haug U, Bretthauer M and Lansdorp-Vogelaar I: Colorectal cancer screening with faecal immunochemical testing, sigmoidoscopy or colonoscopy: A microsimulation modelling study. BMJ 367: 15383-15383, 2019.

11. Obaro AE, Burling DN and Plumb AA: Colon cancer screening with CT colonography: Logistics, cost-effectiveness, efficiency and progress. Br J Radiol 91: 20180307, 2018.

12. Digoras I, Arrospide A, Portillo I, Arana-Arri E, Martínez-IndartL, MarJ, de Koning HJ,Lastra R,Soto-Gordoa M, van der Meulen M and Lansdorp-Vogelaar I: Evaluation of the colorectal cancer screening Programme in the Basque Country (Spain) and its effectiveness based on the Miscan-colon model. BMC Public Health 18: 78, 2017.

13. Arana-Arri E, Idigoras I, Uranga B, Pérez R, Irurzun A, Gutiérrez-Ibarluzea I, Fraser CG and Portillo I; EUSKOLON Group: Population-based colorectal cancer screening programmes using a faecal immunochemical test: Should faecal haemoglobin cut-offs differ by age and sex? BMC Cancer 17: 577, 2017.

14. European Colorectal Cancer Screening Guidelines Working Group; von Karsa L, Patnick J, Segnan N, Atkin W, Halloran S, Lansdorp-Vogelaar I, Malila N, Minozzi S, Moss S, et al: European guidelines for quality assurance in colorectal cancer screening and diagnosis: Overview and introduction to the full supplement publication. Endoscopy 45: 51-59, 2013.

15. Park JS, Kang H, Park SY, Kim HJ, Woo IT, Park IK and Choi GS: Long-term oncologic after robotic versus laparoscopic right colectomy: A prospective randomized study. Surg Endosc 33: 2975-2981, 2019.

16. Kim JC, Lee JL, Yoon YS, Kim CW, Park IJ and Lim SB: Robotic left colectomy with complete mesocolectomy for splenic flexure and descending colon cancer, compared with a laparoscopic procedure. Int J Med Robot 14: e1918, 2018.

17. de'Angelis N, Abdalla S, Bianchi G, Memeo R, Charpy C, Petrucciani N, Sobhani I and Brunetti F: Robotic versus laparoscopic colorectal cancer surgery in elderly patients: A propensity score match analysis. J Laparoendosc Adv Surg Tech A 28: 1334-1345, 2018

18. National Comprehensive Cancer Network: NCCN Clinical Practice Guidelines in Oncology (NCCN Guidelines $\left.{ }^{\circledR}\right)$ : Colon Cancer, 2016. Available from: URL: https://www.nccn. org/professionals/physician_gls/default.aspx.

19. Practice Guidelines in Oncology: (NCCN Guidelines $\left.{ }^{\circledR}\right)$ : Rectal Cancer, 2016. Available from: URL: https://www.ncen. org/professionals/physician_gls/default.aspx.

20. Yao HW, Wu HW and Liu YH: From traditional population-based approach to individualized precision medicine: The interpretation of update on The AJCC Colorectal Cancer Staging System, Eighth Edition. Zhonghua Wai Ke Za Zhi 55: 24-27, 2017 (In Chinese).

21. Tong GJ, Zhang GY, Liu J, Zheng ZZ, Chen Y, Niu PP and Xu XT: Comparison of the eighth version of the American Joint Committee on Cancer manual to the seventh version for colorectal cancer: A retrospective review of our data. World J Clin Oncol 9: 148-161, 2018.

22. Liotta LA and Kohn EC: The microenvironment of the tumour-host interface. Nature 411: 375-379, 2001.

23. Friedl $\mathrm{P}$ and Wolf K: Tumour-cell invasion and migration: Diversity and escape mechanisms. Nat Rev Cancer 3: 362-374, 2003.

24. Guo W and Giancotti FG: Integrin signalling during tumour progression. Nat Rev Mol Cell Biol 5: 816-826, 2004.

25. Xiang Z, Mi Y, Jing H, Li L, Jiong SHI, Baorui L and Xiaoping Q: Expressions of C-MET, COX-2, MSS and Ki-67 in colorectal cancer and correlations with prognosis. J Prev Med Chin PLA 36: 598-601, 20189 (In Chinese).

26. Tong G, Xu W, Zhang G, Liu J, Zheng Z, Chen Y, Niu P and $\mathrm{Xu} \mathrm{X}$ : The role of tissue and serum carcinoembryonic antigen in stages I to III of colorectal cancer-A retrospective cohort study. Cancer Med 7: 5327-5338, 2018.

27. Tian Y, Ma Z, Chen Z, Li M, Wu Z, Hong M, Wang H, Svatek R, Rodriguez $\mathrm{R}$ and Wang Z: Clinicopathological and prognostic value of Ki-67 expression in bladder cancer: A systematic review and meta-analysis. PLoS One 11: e0158891, 2016.

28. Arihiro K, Oda M, Ohara M, Kadoya T, Osaki A, Nishisaka T, Shiroma N and Kobayashi Y: Comparison of visual assessment and image analysis in the evaluation of Ki-67 expression and their prognostic significance in immunohistochemically defined luminal breast carcinoma. Jpn J Clin Oncol 46: 1081-1087, 2016. 
29. Clay V, Papaxoinis G, Sanderson B, Valle JW, Howell M, Lamarca A, Krysiak P, Bishop P, Nonaka D and Mansoor W: Evaluation of diagnostic and prognostic significance of Ki-67 index in pulmonary carcinoid tumours. Clin Transl Oncol 19: 579-586, 2017

30. BerlinA,Castro-MestaJF,Rodriguez-RomoL,Hernandez-BarajasD, González-Guerrero JF, Rodríguez-Fernández IA, González-Conchas G, Verdines-Perez A and Vera-Badillo FE: Prognostic role of Ki-67 score in localized prostate cancer: A systematic review and meta-analysis. In: Urologic Oncology, Seminars and Original Investigations. Elsevier, Amsterdam, 2017.

31. Niazi MKK, Pennell M, Elkins C, Hemminger J, Jin M, Kirby S, Kurt H, Miller B, Plocharczyk E and Roth R: Entropy based quantification of Ki-67 positive cell images and its evaluation by a reader study. In: SPIE Medical Imaging. International Society for Optics and Photonics, Bellingham, p86760I, 2013.

32. Liu Y, Yin W, Yan T, Du Y, Shao Z and Lu J: The clinical significance of $\mathrm{Ki}-67$ as a marker of prognostic value and chemosensitivity prediction in hormone-receptor-positive breast cancer: A meta-analysis of the published literature. Curr Med Res Opin 29: 1453-1461, 2013.

33. Hashimoto Y, Skacel M, Lavery IC, Mukherjee AL, Casey G and Adams JC: Prognostic significance of fascin expression in advanced colorectal cancer: An immunohistochemical study of colorectal adenomas and adenocarcinomas. BMC Cancer 6: 241 2006.

34. Dowsett M, Nielsen TO, A'Hern R, Bartlett J, Coombes RC, Cuzick J, Ellis M, Henry NL, Hugh JC, Lively T, et al: Assessment of Ki67 in breast cancer: Recommendations from the International Ki67 in Breast Cancer working group. J Natl Cancer Inst 103: 1656-1664, 2011.

35. Konsti J, Lundin M, Joensuu H, Lehtimäki T, Sihto H, Holli K, Turpeenniemi-Hujanen T, Kataja V, Sailas L, Isola J and Lundin J: Development and evaluation of a virtual microscopy application for automated assessment of $\mathrm{Ki}-67$ expression in breast cancer BMC Clin Pathol 11: 3, 2011.

36. Mohammed ZM, McMillan DC, Elsberger B, Going JJ, Orange C, Mallon E, Doughty JC and Edwards J: Comparison of visual and automated assessment of Ki-67 proliferative activity and their impact on outcome in primary operable invasive ductal breast cancer. Br J Cancer 106: 383-388, 2012

37. Klauschen F, Wienert S, Schmitt WD, Loibl S, Gerber B, Blohmer JU, Huober J, Rüdiger T, Erbstößer E, Mehta K, et al: Standardized Ki67 diagnostics using automated scoring-Clinical validation in the GeparTrio Breast Cancer Study. Clin Cancer Res 21: 3651-3657, 2015.

38. Wei DM, Chen WJ, Meng RM, Zhao N, Zhang XY, Liao DY and Chen G: Augmented expression of Ki-67 is correlated with clinicopathological characteristics and prognosis for lung cancer patients: An up-dated systematic review and meta-analysis with 108 studies and 14,732 patients. Respir Res 19: 150, 2018.

39. Petrelli F, Viale G, Cabiddu M and Barni S: Prognostic value of different cut-off levels of Ki-67 in breast cancer: A systematic review and meta-analysis of 64,196 patients. Breast Cancer Res Treat 153: 477-491, 2015.

40. Luo ZW, Zhu MG, Zhang ZQ, Ye FJ, Huang WH and Luo XZ: Increased expression of $\mathrm{Ki}-67$ is a poor prognostic marker for colorectal cancer patients: A meta analysis. BMC Cancer 19: 123, 2019.

41. Melling N, Kowitz CM, Simon R, Bokemeyer C, Terracciano L, Sauter G, Izbicki JR and Marx AH: High Ki67 expression is an independent good prognostic marker in colorectal cancer. J Clin Pathol 69: 209-214, 2016

42. Forones NM, Oshima C, Nanogaki S, Tanaka M and Barbosa V: Determination of proliferative activity using Ki67 and expression of p53 in colorectal cancer. Arq Gastroenterol 36: 122-126, 1999 (In Portuguese).

43. Bacher JW, Flanagan LA, Smalley RL, Nassif NA, Burgart LJ, Halberg RB, Megid WM and Thibodeau SN: Development of a fluorescent multiplex assay for detection of MSI-High tumors. Dis Markers 20: 237-250, 2004.

44. Geiersbach KB and Samowitz WS: Microsatellite instability and colorectal cancer. Arch Pathol Lab Med 135: 1269-1277, 2011.

45. Iacopetta B and Watanabe T: Predictive value of microsatellite instability for benefit from adjuvant fluorouracil chemotherapy in colorectal cancer. Gut 55: 1671-1672, 2006.
46. Abubakar M, Howat WJ, Daley F, Zabaglo L, McDuffus LA, Blows F, Coulson P, Raza Ali H, Benitez J, Milne R, et al: High-throughput automated scoring of $\mathrm{Ki} 67$ in breast cancer tissue microarrays from the Breast Cancer Association Consortium. J Pathol Clin Res 2: 138-153, 2016.

47. Abubakar M, Orr N, Daley F, Coulson P, Ali HR, Blows F, Benitez J, Milne R, Brenner H, Stegmaier C, et al: Prognostic value of automated KI67 scoring in breast cancer: A centralised evaluation of 8088 patients from 10 study groups. Breast Cancer Res 18: 104, 2016.

48. Gerdes J, Schwab U, Lemke H and Stein H: Production of a mouse monoclonal antibody reactive with a human nuclear antigen associated with cell proliferation. Int J Cancer 31: 13-20, 1983.

49. Gerdes J, Lemke H, Baisch H, Wacker HH, Schwab U and Stein H: Cell cycle analysis of a cell proliferation-associated human nuclear antigen defined by the monoclonal antibody Ki-67. J Immunol 133: 1710-1715, 1984.

50. Bullwinkel J, Baron-Lühr B, Lüdemann A, Wohlenberg C, Gerdes $\mathrm{J}$ and Scholzen T: Ki-67 protein is associated with ribosomal RNA transcription in quiescent and proliferating cells. J Cell Physiol 206: 624-635, 2006.

51. Miller I, Min M, Yang C, Tian C, Gookin S, Carter D and Spencer SL: Ki67 is a graded rather than a binary marker of proliferation versus quiescence. Cell Rep 24: 1105-1112.e5, 2018.

52. Feng X, Li H, Kornaga EN, Dean M, Lees-Miller SP, Riabowol K, Magliocco AM, Morris D, Watson PH, Enwere EK, et al: Low Ki67/high ATM protein expression in malignant tumors predicts favorable prognosis in a retrospective study of early stage hormone receptor positive breast cancer. Oncotarget 7: 85798-85812, 2016.

53. Shin IY, Sung NY, Lee YS, Kwon TS, Si Y, Lee YS, Oh ST and Lee IK: The expression of multiple proteins as prognostic factors in colorectal cancer: Cathepsin D, p53, COX-2, epidermal growth factor receptor, C-erbB-2, and Ki-67. Gut Liver 8: 13-23, 2014.

54. Scopa CD, Tsamandas AC, Zolota V, Kalofonos HP, Batistatou A and Vagianos C: Potential role of bcl-2 and ki-67 expression and apoptosis in colorectal carcinoma: A clinicopathologic study. Dig Dis Sci 48: 1990-1997, 2003.

55. De Roock W, Claes B, Bernasconi D, De Schutter J, Biesmans B, Fountzilas G, Kalogeras KT, Kotoula V, Papamichael D, Laurent-Puig P, et al: Effects of KRAS, BRAF, NRAS, and PIK3CA mutations on the efficacy of cetuximab plus chemotherapy in chemotherapy-refractory metastatic colorectal cancer: A retrospective consortium analysis. Lancet Oncol 11: 753-762, 2010.

56. Aprile G, Macerelli M, De Maglio G, Pizzolitto S and Fasola G: The relevance of BRAF and extended ras mutational analyses for metastatic colorectal cancer patients. OA Mol Oncol 1: 7, 2013.

57. Kislitsin D, Lerner A, Rennert G and Lev Z: K-ras mutations in sporadic colorectal tumors in Israel: Unusual high frequency of codon 13 mutations and evidence for nonhomogeneous representation of mutation subtypes. Dig Dis Sci 47: 1073-1079, 2002

58. Fransén K, Klintenäs M, Osterström A, Dimberg J, Monstein HJ and Söderkvist P: Mutation analysis of the BRAF, ARAF and RAF-1 genes in human colorectal adenocarcinomas. Carcinogenesis 25: 527-533, 2004.

59. Wong $\mathrm{R}$ and Cunningham $\mathrm{D}$ : Using predictive biomarkers to select patients with advanced colorectal cancer for treatment with epidermal growth factor receptor antibodies. J Clin Oncol 26: 5668-5670, 2008

60. Sartore-Bianchi A, Martini M, Molinari F, Veronese S, Nichelatti M, Artale S, Di Nicolantonio F, Saletti P, De Dosso S, Mazzucchelli L, et al: PIK3CA mutations in colorectal cancer are associated with clinical resistance to EGFR-targeted monoclonal antibodies. Cancer Res 69: 1851-1857, 2009.

61. Shia J, Schultz N, Kuk D, Vakiani E, Middha S, Segal NH, Hechtman JF, Berger MF, Stadler ZK, Weiser MR, et al: Morphological characterization of colorectal cancers in The Cancer Genome Atlas reveals distinct morphology-molecular associations: Clinical and biological implications. Mod Pathol 30: 599-609, 2017.

62. Song GA, Deng G, Bell I, Kakar S, Sleisenger MH and Kim YS: Mucinous carcinomas of the colorectum have distinct molecular genetic characteristics. Int J Oncol 26: 745-750, 2005.

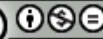

This work is licensed under a Creative Commons Attribution-NonCommercial-NoDerivatives 4.0 International (CC BY-NC-ND 4.0) License. 